\title{
Analysis of the Influence of Coal Petrography on the Proper Application of the Unipore and Bidisperse Models of Methane Diffusion
}

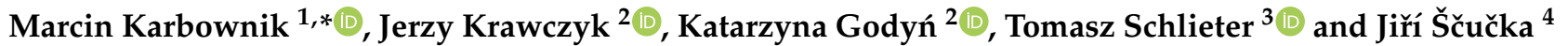 \\ 1 Department of Mining Aerology, Central Mining Institute, Plac Gwarków 1, 40-166 Katowice, Poland \\ 2 The Strata Mechanics Research Institute of Polish Academy of Sciences, Reymonta 27, 30-059 Krakow, Poland; \\ krawczyk@img-pan.krakow.pl (J.K.); godyn@img-pan.krakow.pl (K.G.) \\ 3 Department of Computational Mechanics and Engineering, Silesian University of Technology, \\ Konarskiego 18A, 44-100 Gliwice, Poland; Tomasz.Schlieter@polsl.pl \\ 4 Institute of Geonics of the CAS, Studentská 1768, 70800 Ostrava, Czech Republic; jiri.scucka@ugn.cas.cz \\ * Correspondence: mkarbownik@gig.eu; Tel.: +48-32-324-65-03
}

check for

updates

Citation: Karbownik, M.; Krawczyk, J.; Godyń, K.; Schlieter, T.; Ščučka, J. Analysis of the Influence of Coal Petrography on the Proper Application of the Unipore and Bidisperse Models of Methane Diffusion. Energies 2021, 14, 8495. https://doi.org/10.3390/en14248495

Academic Editors: Yosoon Choi and Sung-Min Kim

Received: 29 October 2021

Accepted: 13 December 2021

Published: 16 December 2021

Publisher's Note: MDPI stays neutral with regard to jurisdictional claims in published maps and institutional affiliations.

Copyright: (c) 2021 by the authors. Licensee MDPI, Basel, Switzerland. This article is an open access article distributed under the terms and conditions of the Creative Commons Attribution (CC BY) license (https:/ / creativecommons.org/licenses/by/ $4.0 /)$.

\begin{abstract}
The analysis of phenomena related to gas transport in hard coal is important with regard to the energetic use of coal bed methane (CBM), the reduction of greenhouse gas emissions to the atmosphere $\left(\mathrm{CO}_{2}\right)$ and the prevention of natural hazards such as methane hazards and gas and rock outbursts. This article presents issues concerning the feasibility and scope of applying the unipore and bidisperse diffusion models to obtain knowledge concerning the kinetics of methane sorption and its diffusion in the carbon structure, depending on its petrography. Laboratory tests were carried out on coal samples which varied in terms of petrography. Quantitative point analyses were carried out, based on which content of groups of macerals was determined. The degree of coalification of coal samples was also determined based on measurements of vitrinite reflectivity $R_{0}$ and the volatile matter content $V^{\text {daf }}$. Sorption kinetics were also investigated, and attempts were made to adjust the unipore and bidisperse models to the real sorption kinetic courses. This allowed the identification of appropriate coefficients controlling the course of sorption in mathematical models. An attempt was also made to assess the possibility of applying a given model to properly describe the phenomenon of methane sorption on hard coal.
\end{abstract}

Keywords: hard coal; sorption; petrography; gas transport; diffusion models; coal bed methane; natural hazards

\section{Introduction}

Global economic development and the growth of civilization itself lead to greater consumption of electricity, resulting in a constant increase in the demand for it [1]. Its primary source is fossil fuels (mainly coal), the use of which causes the emission into the atmosphere of many harmful chemical compounds, including greenhouse gases (mainly $\mathrm{CO}_{2}$ ), which cause global warming [2-4]. As a result of international agreements concluded under the United Nations Framework Convention on Climate Change (UNFCCC), countries are required to reduce greenhouse gas (GHG) emissions, especially $\mathrm{CO}_{2}$, which has resulted in increased demand for "clean energy" sources. Currently, there is a growing awareness of the fact that methane molecules have a much greater impact on the greenhouse effect than carbon dioxide. This justifies research into the processes determining its emission into the atmosphere $[5,6]$.

Coalbed methane (CBM) is a gas of natural origin, which was formed as a result of processes of conversion of organic matter into coal [7]. It occurs in coal seams mainly as adsorbed gas and in smaller amounts, also as free gas. This gas is of great importance worldwide as an alternative energy source [8-10]. Poland has some of the largest hard coal deposits in Europe, accompanied by the presence of methane. The unit methane content in 
coal seams reaches several cubic meters per ton of coal $\left(\mathrm{m}^{3} \mathrm{CH}_{4} / \mathrm{t}\right)$, which in the scale of the entire Upper Silesian Coal Basin (GZW), results in trillions of cubic meters of gas [11,12]. The capture of coalbed methane is desirable both from the point of view of energy, safety and environmental protection, because it is released during mining operations and is a source of danger and contributes to the increase in the greenhouse effect [13]. The study of gas transport phenomena in the coal structure is crucial for both the evaluation of coalbed methane production and $\mathrm{CO}_{2}$ sequestration, due to the fact that the coal matrix is the main site for gas storage, sorption, and diffusion [14-16].

Gas sorption and desorption in coal is a complex process. For a long time, attempts were made to describe it using relatively simple mathematical models. They assumed that it was sufficient to take into account selected processes which were most important for the course of the phenomenon. For some coals, a good fit of the simulation results to the experimental data could be obtained. This may indicate that the processes included in the assumptions of the models are in fact the most significant for the course of the phenomenon, and the parameters of the model may be used to evaluate the properties of the material studied. The kinetics of the processes of methane accumulation and release within the coal structure depend on many factors. These coefficients are the effective diffusion coefficient $\left(D_{e}\right)$, the sorption capacity (a) and the half sorption time $\left(\mathrm{t}_{1 / 2}\right)$, which describe the kinetics of methane sorption on hard coal. Under certain assumptions, the key element affecting the rate of methane accumulation/release in hard coal will be the internal structure of the tested coal material [17]. One of the crucial parameters characterizing the kinetics of methane sorption in coal is the effective diffusion coefficient $D_{e}$. It is obtained from the solution of Fick's second law [18] using a number of simplifying assumptions. One of them is the assumption that the coal matrix contains only one type of pore-micropores. In reality, there are at most two different (interrelated) mechanisms related to the diffusion of methane from the microporous matrix and the flows occurring in the interstices and macropores [19]. In Poland, at present, the unipore model is used only to describe the kinetics of methane sorption on coal [20].

The literature survey conducted shows that there is a significant correlation between coal petrography and gas diffusion kinetics [21-26]. The change in porous structure is closely related to the change in the degree of coalification, and pores vary in shape and size [27]. The diffusivity of coal was found to decrease degree of coalification increased due to an increase in the proportion of micropores in its structure [28]. Based on research, the achievement of sorption equilibrium was found to be faster for low rank coals than for high rank coals [29].

The processes of gas desorption, sorption and migration were also modelled using numerical methods [21,30-33]. Determining the parameters of the bidisperse model allows it to be used for numerical analyses. By comparing the results for both descriptions of sorption kinetics, it was possible to assess the extent to which using a more accurate description can affect the quality of numerical modelling.

In this paper, an attempt is made to determine the possible scope of using the unipore and bidisperse model to obtain knowledge concerning the kinetics of methane sorption and its diffusion in the coal structure. Due to the range of different types and kinds of hard coal and its extended structure, it is not possible to precisely describe the kinetics of methane sorption in a universal way, based on simplified formulas that do not take into account the variability of its structure and the type of pores (micropores and macropores).

This article presents the results of laboratory analyses of sorption and petrography for coal samples collected from mines located in the Upper Silesian Coal Basin. The coals selected for the analyses are characterised by a variable degree of coalification and diversified physical and chemical parameters. Within the scope of the paper, model runs were fitted to the measured kinetics of the sorption process on hard coal using unipore and bidisperse models, which allowed the determination of the corresponding coefficients found in the mathematical models. Thus far, only the first model has been used to describe the kinetics of methane sorption on hard coal, describing the sorption/diffusion kinetics 
using the effective diffusion coefficient from Crank's solution [20]. The research carried out within the scope of this paper will allow us to assess the quality of model descriptions and to determine the coal properties (maceral composition, degree of coalification) for which it is possible to apply the unipore model and, when it becomes necessary, to apply the bidisperse model. These considerations relate to coals from the Upper Silesian Coal Basin, whereas the results obtained, due to the diversity of samples analysed, may be applied to hard coals globally.

\section{Diffusion Models}

\subsection{Unipore Diffusion Model}

The most common and widely used physical model to describe sorption kinetics and methane diffusion phenomenon in hard coal is the unipore model [17,25,34-37]. It assumes that the carbon matrix is homogeneous and is composed of a single type of pores in which the diffusion and sorption processes occur at equal rates [32,38-40]. A number of assumptions and simplifications are required to make the unipore model practical $[17,41]$.

The physical dependence that quantitatively describes the diffusion process is Fick's second law and is the basis for the derivation of the unipore model [18]:

$$
\frac{\partial c}{\partial t}=D \cdot \nabla^{2} c
$$

where $c$ - substance concentration $\left(\mathrm{mol} / \mathrm{m}^{3}\right), t$ - time $(\mathrm{s}), D$-diffusion coefficient $\left(\mathrm{m}^{2} / \mathrm{s}\right)$.

An analytical solution of the model, which relates to Fick's second law, can be found in Crank [20] and Timofiejew [42]:

$$
\frac{\partial c(r, t)}{\partial t}=\frac{D}{1+K_{H}} \nabla^{2} c(r, t)=D_{e} \nabla^{2} c(r, t) ; \quad D_{e}=\frac{D}{1+K_{H}}
$$

where $D_{e}$-effective diffusion coefficient $\left(\mathrm{cm}^{2} / \mathrm{s}\right), K_{H}$ 一 Henry's linear isotherm coefficient $(\mathrm{mol} / \mathrm{g} \times \mathrm{bar}), r$-distance from the centre of the grain $(\mathrm{m})$.

With the required assumptions, the solution of Equation (2) under certain boundary and initial conditions, as described in the literature [20,37,42], takes the form:

$$
\frac{M_{t}}{M_{\infty}}=1-\frac{6}{\pi^{2}} \sum_{n=1}^{\infty} \frac{1}{n^{2}} \exp \left(-\frac{D_{e} n^{2} \pi^{2} t}{R_{z}^{2}}\right) ; \quad R_{z}=\frac{1}{2} \sqrt[3]{\frac{2 d_{1}^{2} d_{2}^{2}}{d_{1}+d_{2}}}
$$

where $M_{t}$-mass of gas deposited in time $t(\mathrm{~g}), M_{\infty}$-total mass of gas deposited in grains $(\mathrm{g}), R_{z}$ - substitute grain radius $(\mathrm{cm}), d_{1}$ and $d_{2}$-grain boundary values for the examined grain class $[\mathrm{cm}]$.

\subsection{Bidisperse Diffusion Model}

The second model to be analysed is the bidisperse model. Its primary assumption is that the coal matrix is a spherical particle that is formed from an agglomeration of multiple microporous spheres with macropores around the microparticles [32], as shown schematically in Figure 1. This model was first developed and described by Ruckenstein [43].

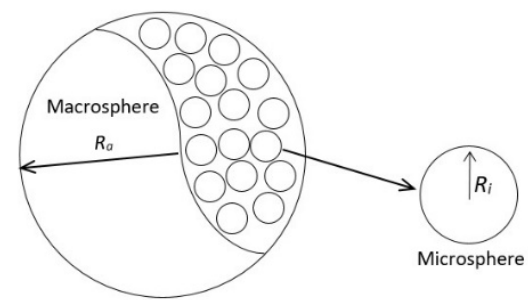

Figure 1. Schematic representation of the coal matrix with micro- and macropores present as assumed by the bidisperse model [43]. 
The bidisperse model [28,30,34,44-48] assumes that the coal matrix consists of a microand macropore system, described by the diffusion coefficients $D_{i}$ and $D_{a}$, respectively. Gas diffusion in the bidisperse system is driven by the concentration gradient between the outer and inner parts of the system.

The equations describing gas diffusion into macro- and microsphere particles are presented as follows [32]:

$$
\frac{D_{a} \epsilon_{a}}{r_{a}^{2}} \frac{\partial}{\partial r_{a}}\left(r_{a}^{2} \frac{\partial C_{a}}{\partial r_{a}}\right)=\epsilon_{a} \frac{\partial C_{a}}{\partial t}+S_{a} \frac{\partial C_{s a}}{\partial t}+4 \pi n R_{i}^{2} \epsilon_{i} D_{i}\left(\frac{\partial C_{i}}{\partial r_{i}}\right)_{r_{i}=R_{i}}
$$

where $D_{a}$-diffusion coefficient for macropores $\left(\mathrm{cm}^{2} / \mathrm{s}\right), D_{i}$-diffusion coefficient for micropores $\left(\mathrm{cm}^{2} / \mathrm{s}\right), r_{a}$ - distance from the centre of macropores $(\mathrm{cm}), C_{a}$-macropore fluid phase sorbate concentration $\left(\mathrm{mol} / \mathrm{cm}^{3}\right), C_{s a}$-macropore adsorber phase concentration $\left(\mathrm{mol} / \mathrm{cm}^{2}\right), n$-number of microspheres per unit volume of the macrosphere, $R_{i}-$ microsphere radius $(\mathrm{cm}), S_{a}$-macropore surface $\left(\mathrm{cm}^{2} / \mathrm{cm}^{3}\right), \epsilon_{a}$-macropore void fraction, $\epsilon_{i}$-micropore void fraction, $t$-time (s).

$$
\frac{D_{i} \epsilon_{i}}{r_{i}^{2}} \frac{\partial}{\partial r_{i}}\left(r_{i}^{2} \frac{\partial C_{i}}{\partial r_{i}}\right)=\epsilon_{i} \frac{\partial C_{i}}{\partial t}+S_{i} \frac{\partial C_{s i}}{\partial t}
$$

where $C_{i}$-micropore fluid phase sorbate concentration $\left(\mathrm{mol} / \mathrm{cm}^{3}\right), C_{s}$-micropore adsorber phase concentration $\left(\mathrm{mol} / \mathrm{cm}^{2}\right), S_{i}$-micropore surface $\left(\mathrm{cm}^{2} / \mathrm{cm}^{3}\right), r_{i}$-distance from the centre of micropores $(\mathrm{cm})$.

The mathematical solutions of the above partial differential equations are complicated. To enable them to be easily fitted to experimental data, Ruckenstein [43] provided a simplified solution. Its basic assumption is that the sorption and diffusion processes occur much faster in macropores than in micropores; thus, the process was divided into two stages: a slower stage, occurring in micropores, and a faster stage, occurring in macropores. Accepting the above assumptions, the equations take the following form:

$$
\frac{M_{a}}{M_{a \infty}}=1-\frac{6}{\pi^{2}} \sum_{n=1}^{\infty} \frac{1}{n^{2}} \exp \left(-\frac{D_{a}^{\prime} n^{2} \pi^{2} t}{R_{a}^{2}}\right)
$$

where: $M_{a}$-mass of gas deposited in macropores in time $t(\mathrm{~g}), M_{a \infty}$-total mass of gas deposited in macropores $(\mathrm{g}), R_{a}$-macrosphere radius $(\mathrm{cm}), D_{a}^{\prime}$-effective diffusion coefficient for macropores $\left(\mathrm{cm}^{2} / \mathrm{s}\right)$.

$$
\frac{M_{i}}{M_{i \infty}}=1-\frac{6}{\pi^{2}} \sum_{n=1}^{\infty} \frac{1}{n^{2}} \exp \left(-\frac{D_{i}^{\prime} n^{2} \pi^{2} t}{R_{i}^{2}}\right)
$$

where $M_{i}$-mass of gas deposited in micropores in time $t(\mathrm{~g}), M_{i \infty}$-total mass of gas deposited in micropores $(\mathrm{g}), D_{i}^{\prime}$-effective diffusion coefficient for micropores $\left(\mathrm{cm}^{2} / \mathrm{s}\right)$.

Hence, the total sorption at any time can be represented as the sum of the sorption of the macrosphere and microsphere in the form of the following equation:

$$
\frac{M_{t}}{M_{\infty}}=\frac{M_{a}+M_{i}}{M_{a \infty}+M_{i \infty}}=\frac{\frac{M_{a}}{M_{a \infty}}+\frac{M_{i}}{M_{i \infty}}\left(\frac{M_{i \infty}}{M_{a \infty}}\right)}{1+\frac{M_{\infty}}{M_{a \infty}}}=\frac{\frac{M_{a}}{M_{a \infty}}+\frac{\beta}{3 \alpha} \frac{M_{i}}{M_{i \infty}}}{1+\frac{\beta}{3 \alpha}}
$$

where $\alpha$-dimensionless parameter specified:

$$
\alpha=\frac{D_{i}^{\prime} R_{a}^{2}}{D_{a}^{\prime} R_{i}^{2}}
$$


where $\beta$-dimensionless parameter specified:

$$
\beta=\left[3 \frac{\left(1-\epsilon_{a}\right) \epsilon_{i}}{\epsilon_{a}}\right]\left(\frac{D_{i}^{\prime} R_{a}^{2}}{D_{a}^{\prime} R_{i}^{2}}\right)
$$

Accepting the presented assumptions, the equation for the bidisperse model, which takes into account the sorption and diffusion processes occurring independently in microand macropores, takes the form:

$$
\frac{M_{t}}{M_{\infty}}=\frac{\left[1-\frac{6}{\pi^{2}} \sum_{n=1}^{\infty} \frac{1}{n^{2}} \exp \left(-\frac{D_{a}^{\prime} n^{2} \pi^{2} t}{R_{a}^{2}}\right)\right]+\frac{\beta}{3 \alpha}\left[1-\frac{6}{\pi^{2}} \sum_{n=1}^{\infty} \frac{1}{n^{2}} \exp \left(-\frac{D_{i}^{\prime} n^{2} \pi^{2} t \alpha}{R_{i}^{2}}\right)\right]}{1+\frac{\beta}{3 \alpha}}
$$

\section{Materials and Methods}

\subsection{Materials}

Coal samples from the Upper Silesian Coal Basin (USCB), both from the Polish and Czech parts, were selected for the study. The samples were taken from the following mines: from the Polish part samples were taken from Sobieski (D-25, D-24), Piast (D-34), Mysłowice-Wesoła (D-37), Borynia (D-6), Zofiówka (D-22, D-23), and Pniówek (D-7); from the Czech part samples were taken from the ČR-Věřnovice mine (Cz. 4032, Cz. 4006). In the remainder of this article, samples will be named according to their symbols. The research material is characterized by varied petrography. Coals which differ in their degree of coalification and maceral composition were used for the tests. The samples were grouped according to their degree of coalification and summarized in Table 1.

\begin{tabular}{|c|c|c|}
\hline Low-Rank Coal Samples & Medium-Rank Coal Samples & High-Rank Coal Samples \\
\hline Sobieski D-25 & Borynia D-6 & \\
\hline Sobieski D-24 & Zofiówka D-22 & ČR-Věřňovice Cz. 4006 \\
\hline Piast D-34 & Pniówek D-7 & \\
\hline Mysłowice-Wesoła D-37 & Zofiówka D-23 & CR-Veěrnovice Cz. 4032 \\
\hline
\end{tabular}

Table 1. Coal samples selected for testing, taken from the Upper Silesian Coal Basin.

\subsection{Petrographic Analysis-Research of Vitrinite Reflectivity and Maceral Composition}

As part of the petrographic research, a quantitative point analysis and measurements of the coalification degree of selected coal samples from the USCB area were performed. The above analyses were conducted in accordance with recommendations of the International Committee for Coal and Organic Petrology (ICCP) regarding the petrographic analysis of hard coal and anthracite, contained in standards ISO 7404-2:2005-for preparing coal samples [49], ISO 7404-3:2001—for determining maceral group composition [50] and ISO 7404-5:2002 - for reflectance of vitrinite [51]. Petrographic analyses were performed on granular polished sections according to the recommendation of ISO standards (ISO 7404-2; ISO 7404-3).

An AXIOPLAN polarizing microscope by ZEISS and a computer-controlled XYZ mechanical table were used to perform petrographic analyses. The image from under the optical microscope is transmitted to a monitor by a CCD camera. The relevant measurements were performed at $500 \times$ magnification using oil immersion.

To assess the content of individual maceral groups, quantitative point analyses were conducted. They included the determination of the content of the vitrinite, liptinite and inertinite groups as well as the mineral substance. Quantitative analyses were carried out on 1500 measurement points located in a square grid covering approx. $80 \%$ of the granular polished sections. The analyses of the maceral composition of individual samples are complemented by photographs of interesting fragments of the analysed coals. 
For each of the analysed samples, the $R_{0}$ reflectivity was measured on the macerals from the vitrinite group colotelinite-free of impurities and inclusions. An Olympus BX50 polarization microscope at a magnification of $400 \times$ was used for the measurements. The granular polished sections were analysed in monochromatic light with a set wavelength of $\lambda=546 \mathrm{~nm}$, reflected from the vitrinite surface, using oil immersion with a refractive index of $n=1.518$. The results were obtained using the "LUCIA Vitrinite" image analysis system.

The volatile matter content was determined by the weight method based on the requirements of the Polish standard PN-G-04516 [52]. It consists of measuring the loss of volatile decomposition products of solid fuel, which is formed as a result of heating at $850{ }^{\circ} \mathrm{C}$ for $7 \mathrm{~min}$ without air access. An analytical sample with grain size below $0.2 \mathrm{~mm}$, which is in accordance with the requirements of the standard, was used for the tests. The final result was obtained by converting the measured value to the dry, ash-free state (daf).

\subsection{Sorption Analysis-Determination of Sorption Kinetics}

A Hiden Isochema IGA-001 gravimetric sorption system was used for the precise analysis of sorption kinetics. The research on methane sorption was carried out on the basis of the gravimetric (weight) method, which, compared to the widely used volumetric method, is characterized by much greater accuracy and the possibility of registering the kinetics of the process.

The IGA-001 is an advanced gravimetric apparatus that records changes in sample mass over time associated with sorption processes occurring in porous materials, including coal. The sorption test stand described above is presented in Figure 2.

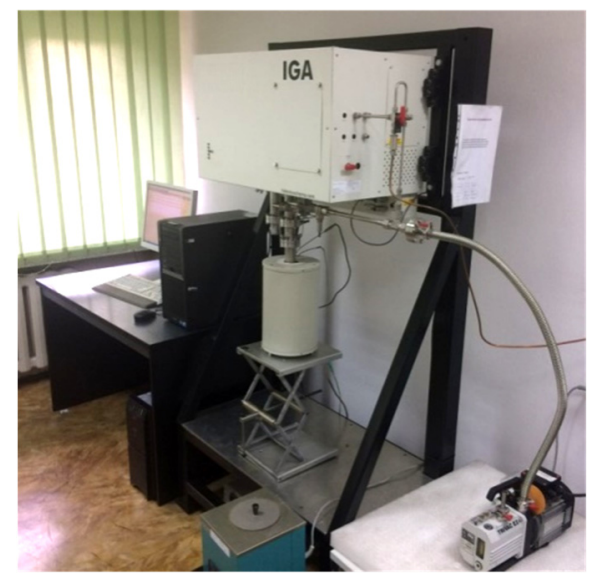

Figure 2. IGA-001 (intelligent gravimetric analyser) sorption test rig.

Coal samples with a grain size of $0.2-0.25 \mathrm{~mm}$ and a mass of approximately $150 \mathrm{mg}$ were used for sorption testing. In the first stage, the sample was degassed and heated at $98^{\circ} \mathrm{C}$ to remove adsorbed impurities and moisture.

After setting a certain pressure for the isotherm point, the sample mass is analysed continuously (real-time kinetic analysis). Data are collected until the previously set criterion approaches equilibrium. At this point, the software records the asymptotic adsorption and other equilibrium readings, and the pressure is automatically changed to a higher set point. The sorption kinetics are recorded continuously for each sorption isotherm point. The sorption isotherms for each coal samples were determined at 2 pressure points: 0.1 and $0.8 \mathrm{MPa}$, under continuously controlled temperature conditions of $25^{\circ} \mathrm{C}$. In the following part of the article, the sorption kinetics determined at $0.1 \mathrm{MPa}$ will be analysed.

\subsection{Identification Procedure}

In order to determine the parameters describing the course of the sorption process on the basis of experimental data, an identification procedure was developed. The data obtained from experimental sorption tests were transformed to a system with the ratio 
$\frac{M_{t}}{M_{\infty}}(t)$ of gas adsorbed at the time $t$ to the total mass of gas adsorbed in grains. Therefore, the experimental sorption curves were obtained, which were compared with the model described by Equation (3) in the case of the unipore model and Equation (11) in the case of the bidisperse model. The choice of the most appropriate of the two models depends on the structure of the analysed samples. The identification procedure is carried out as a task of minimisation of the error measure between the experimental and the model course of sorption curves. The error measure adopted in the task was the mean square error (MSE). In the identification problem defined in this way, the objective function $J$ is minimised:

$$
J=\sum_{j=1}^{M}\left(\hat{q}_{j}-q_{j}\right)^{2}
$$

where $\hat{q}_{j}$ is the measured value of the ratio $\frac{M_{t}}{M_{\infty}}, q_{j}$ is the value of $\frac{M_{t}}{M_{\infty}}$ determined from the corresponding equation modelling the course of sorption at the same time, and $M$ is the number of measurements. The actual measurements were made at varying times, with a higher frequency at the initial stage of the process. The number of measurements depended on the time required to reach the equilibrium state which corresponds with the value of $\frac{M_{t}}{M_{\infty}}=1$. The number of measurements ranges from about 250 to 500 , depending on the experiment. The infinite sequences in the equations were approximated using the first 30 terms; it has been noted in previous studies that even approximation to 10 terms provides satisfactory results [53]. The parameter to be identified in the case of the unipore model is $\frac{D_{e}}{R_{z}^{2}}$, and after assuming a known value of $R_{z}$ it is possible to determine the effective diffusion coefficient $D_{e}$. For the bidisperse model, which is described by a larger number of parameters, the following quantities were identified: $\frac{D_{a}^{\prime}}{R_{a}^{2}}, \frac{D_{i}^{\prime}}{R_{i}^{2}}, \alpha, \frac{\beta}{\alpha}$ The function fmincon in MATLAB software was used to solve the identification task. This function searches for the minimum of a function with constraints using the interior-point method algorithm.

\section{Results and Discussion}

\subsection{Petrographic Analysis}

Hard coal, depending on the degree of coalification (determined on the basis of $R_{0}$ and $V^{\text {daf }}$ ), differs in colour in the microscopic view. The main difference can be seen in the grey shades of the individual macerals. In low rank coals, vitrinite is dark grey, liptinite is almost black, and inertinite is grey. In samples with higher coalification the macerals turn a slightly lighter shade of grey. In high rank coals vitrinite is almost white, while liptinite is completely invisible. During the microscopic research, photographic documentation of interesting fragments of the investigated coals was made. The above microscopic images are presented in the form of photographs in Figure $3 a-j$. 


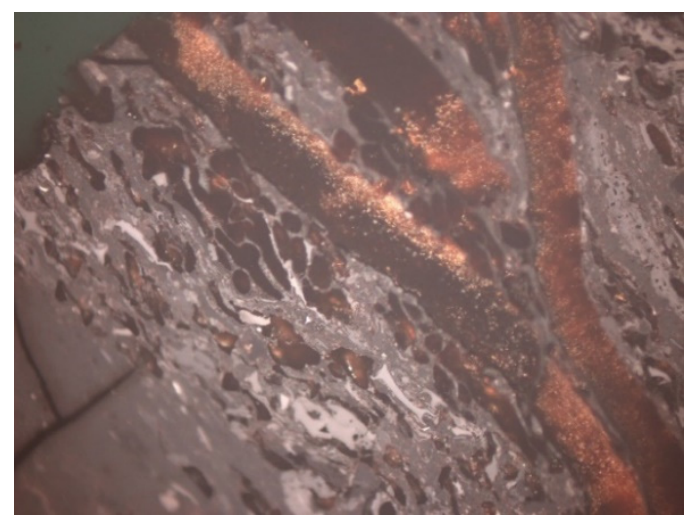

(a)

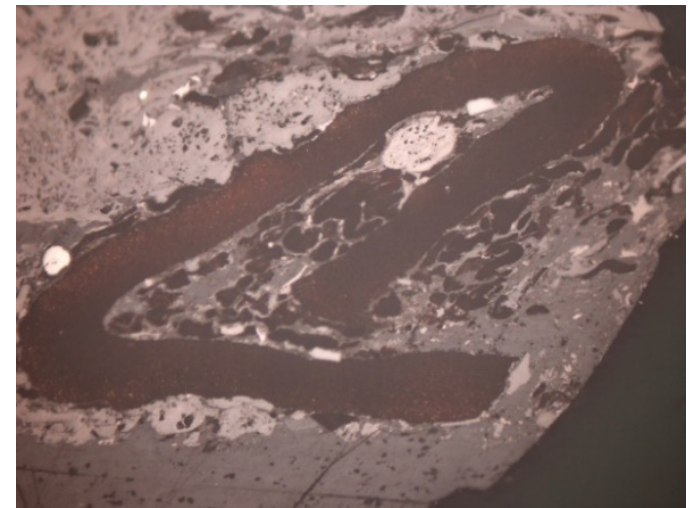

(c)

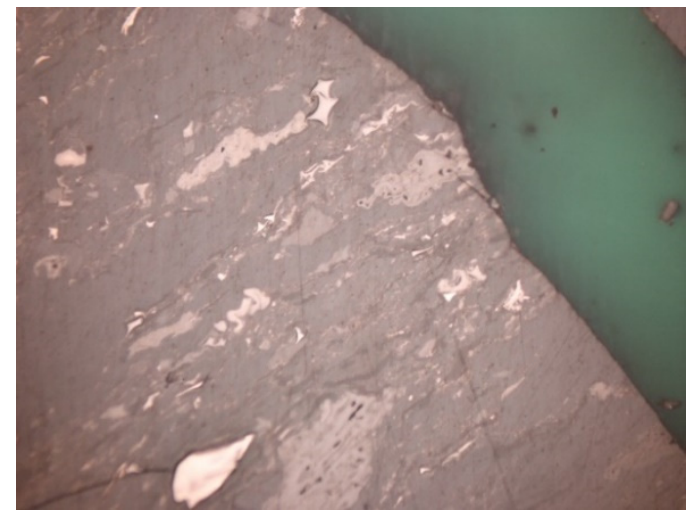

(e)

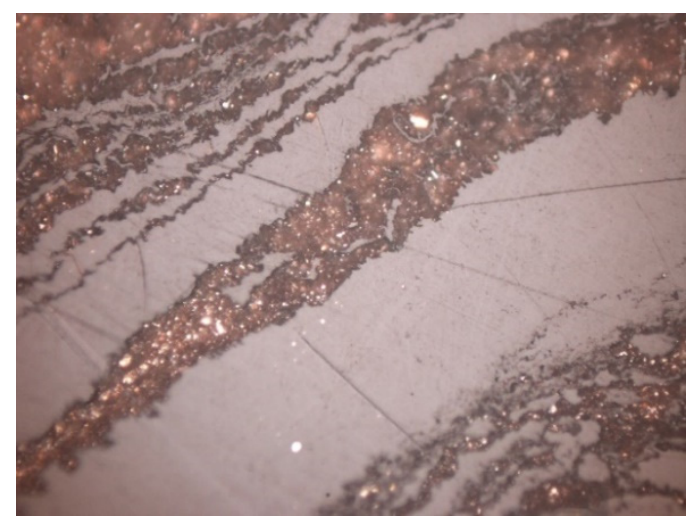

(g)

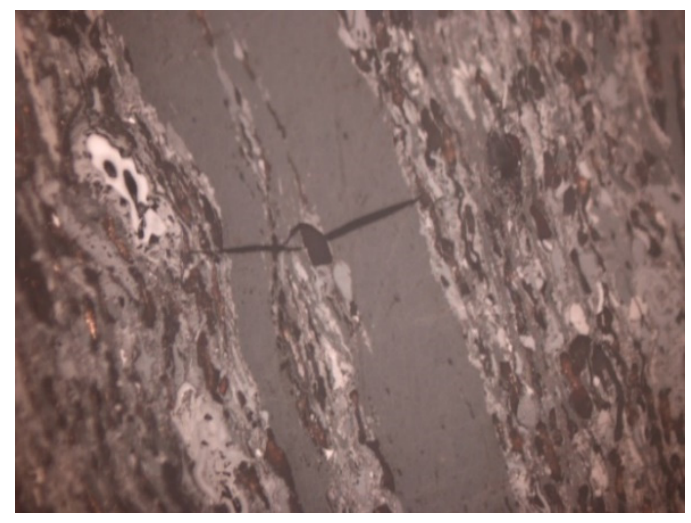

(b)

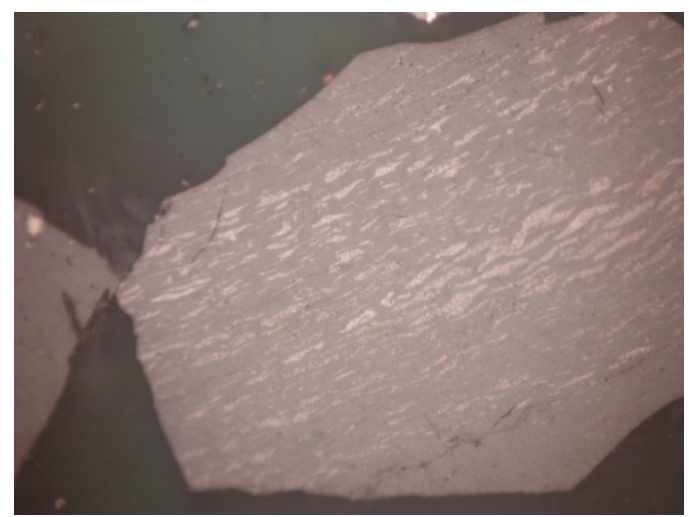

(d)

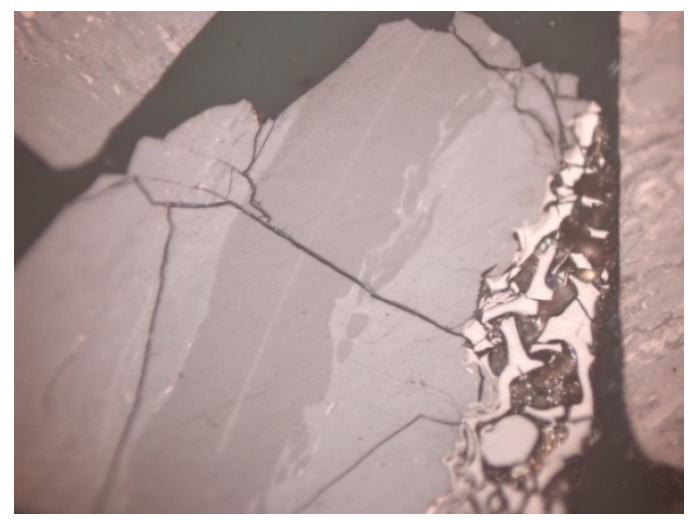

(f)

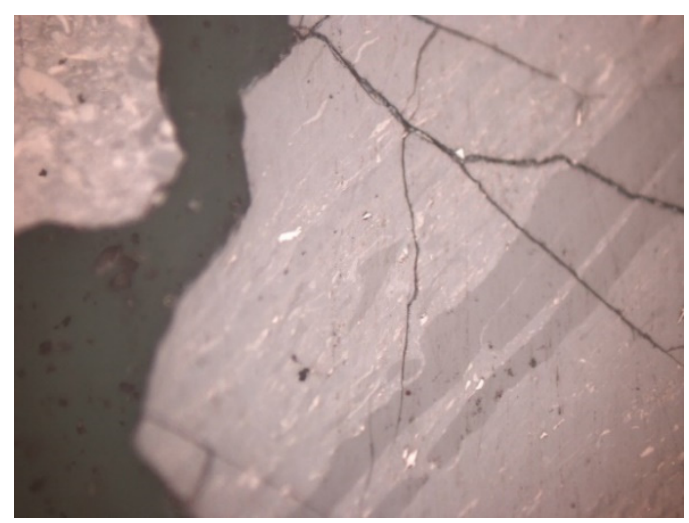

(h)

Figure 3. Cont. 


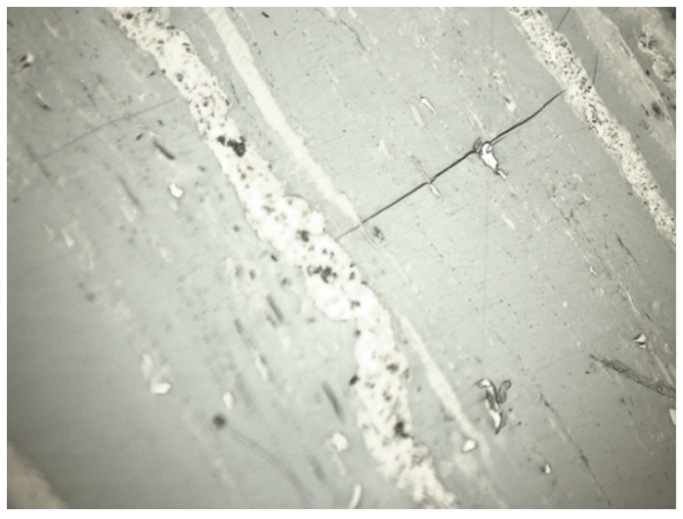

(i)

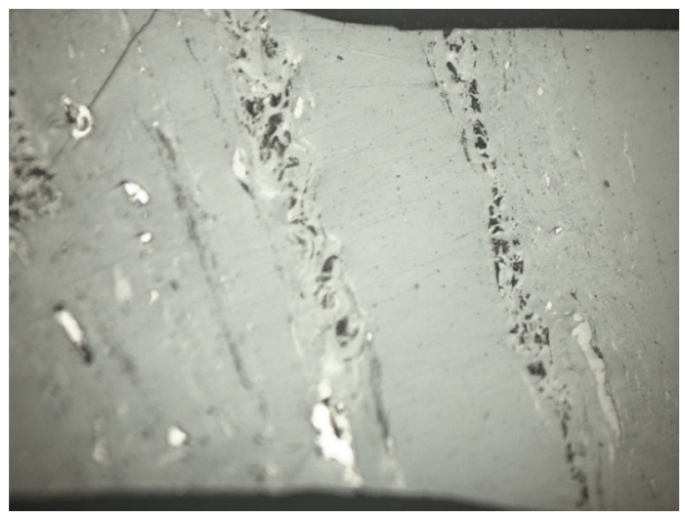

(j)

Figure 3. (a) D-25—sporinite (macro and microscopic) surrounded by vitrinite and inertinite; (b) D-24-lamina of cracked vitrinite surrounded by trimacerite; (c) D-34-macro- and microsporinite among macerals of vitrinite and inertinite group; (d) D-37-telinite impregnated with micrinite; (e) D-6-fragment of coal composed of vitrinite and scattered macerals of inertinite and liptinite group; (f) D-22-fragment of lightly cracked coal composed of vitrinite and large macrospore and inertinite fragments; (g) D-7-vitrinite with bands of mineral matter, mainly clay; (h) D-23-fragment of coal composed of colotelinite, sporinite and small fragments of inertodetrinite; (i) Cz. 4032-vitrinite with macerals of inertinite group; (j) Cz. 4006 - vitrinite with macerals of the inertinite group. Magnification 500×, reflected light, immersion.

Table 2 presents the results of petrographic microscopic analyses, along with quantitative point analysis and vitrinite reflectance. Furthermore, the results of some technical analyses such as moisture content $W_{a}$, ash content $A$ and volatile matter content $V^{\text {daf }}$ are included. The content of each group of macerals was converted to mineral matter free (mmf), and the content of mineral substance for each sample was also given.

Table 2. Results of petrographic analyses.

\begin{tabular}{|c|c|c|c|c|c|c|c|c|c|}
\hline No. & Sample & $\begin{array}{l}W_{a} \\
(\%)\end{array}$ & $\begin{array}{c}A \\
(\%)\end{array}$ & $\begin{array}{l}V^{d a f} \\
(\%)\end{array}$ & $\begin{array}{l}R_{0} \\
(\%)\end{array}$ & $\begin{array}{c}\text { Wt mmf } \\
(\%)\end{array}$ & $\begin{array}{c}\text { I } \mathrm{mmf}_{(\%)} \\
\text { (\%) }\end{array}$ & $\begin{array}{c}\mathrm{L} \mathbf{m m f} \\
(\%)\end{array}$ & $\begin{array}{c}\text { Minerals } \\
(\%)\end{array}$ \\
\hline \multicolumn{10}{|c|}{ Low rank coals } \\
\hline 1. & D-25 & 11.59 & 8.63 & 35.12 & 0.435 & 58.69 & 32.27 & 9.04 & 1.64 \\
\hline 2. & D-24 & 8.04 & 8.03 & 36.73 & 0.47 & 47.56 & 39.68 & 12.75 & 5.68 \\
\hline 3. & D-34 & 3.49 & 5.92 & 38.58 & 0.716 & 58.32 & 24.27 & 17.41 & 1.95 \\
\hline 4. & D-37 & 3.17 & 12.08 & 38.96 & 0.735 & 64.99 & 28.89 & 6.12 & 6.60 \\
\hline \multicolumn{10}{|c|}{ Medium rank coals } \\
\hline 5. & D-6 & 1.53 & 4.01 & 25.05 & 1.076 & 87.65 & 9.53 & 2.82 & 0.53 \\
\hline 6. & D-22 & 1.12 & 5.80 & 25.37 & 1.113 & 81.55 & 15.87 & 2.57 & 3.28 \\
\hline 7. & $\mathrm{D}-7$ & 1.47 & 29.35 & 27.07 & 1.116 & 80.20 & 18.60 & 1.20 & 21.7 \\
\hline 8. & D-23 & 0.99 & 6.21 & 19.80 & 1.361 & 73.82 & 24.09 & 2.09 & 6.83 \\
\hline \multicolumn{10}{|c|}{ High rank coals } \\
\hline 9. & Cz. 4006 & 0.62 & 7.54 & 13.62 & 1.94 & 91.29 & 8.71 & 0 & 3.11 \\
\hline 10 & Cz. 4032 & 0.60 & 9.02 & 13.51 & 2.01 & 88.18 & 11.82 & 0 & 2.62 \\
\hline
\end{tabular}

Based on the research results, it was assumed that:

- $\quad$ Samples with $R_{0}<1 \%$ should be treated as low rank coals (acc. to ASTM-Subbituminous and High Volatile Bituminous) [54].

- Samples with $R_{0} 1-1.4 \%$ should be treated as medium rank coals (acc. to ASTMMedium Volatile Bituminous) [54].

- Samples with $R_{0}>1.4 \%$ should be treated as high rank coals (acc. to ASTM-Low Volatile Bituminous) [54]. 
Vitrinite reflectivity $R_{0}$ for the analysed coal samples ranged from $0.435 \%$ to $2.01 \%$. The lowest value of $0.435 \%$ was recorded for coal sample D-25, while the highest, i.e., $2.01 \%$, was recorded for sample Cz. 4032. On the basis of the reflectivity test results and the assumptions made above, samples D-25, D-24, D-34 and D-37 were classified as low rank coals, samples D-6, D-22, D-7 and D-23 as medium rank coals, and samples Cz. 4006 and Cz. 4032 as high rank coals.

After analysing the obtained results of maceral composition, it was observed that the vitrinite content for all the tested samples ranged from $47.56 \%$ to $91.29 \%$. For low rank coal samples, the values ranged from $47.56 \%$ to $64.99 \%$, with the lowest value of $47.56 \%$ recorded for coal sample D-24. For medium rank coal samples, the values ranged from $73.82 \%$ to $87.65 \%$, and for high rank coal samples from $88.18 \%$ to $91.29 \%$. The highest vitrinite content of $91.29 \%$ was recorded for sample Cz. 4006.

The content of inertinite in the analysed samples ranged from $8.71 \%$ to $39.68 \%$. The highest value was recorded for sample D-24, which is one of the low rank coals, while the lowest value, i.e., $8.71 \%$ was recorded for sample Cz. 4006, which is one of the high rank coals. The inertinite content for medium rank coals ranged from $9.53 \%$ to $24.09 \%$.

In the samples with a high degree of coalification (Cz. 4032 and Cz. 4006), no macerals from the liptinite group were observed. This effect is known as the vitrinization of liptinite. Such a process causes the optical similarity of liptinite to vitrinite. Therefore, in microscopic observations in samples with $R_{0}$ above 1.3-1.4, macerals of the liptinite group are invisible. In the case of medium rank coals, liptinite was present in the range of $1.20 \%$ to $2.82 \%$. Its highest values were observed for coal samples with a low degree of coalification. Their results ranged from $6.12 \%$ to $17.41 \%$, and the highest value, i.e., $17.41 \%$ was obtained for the D-34 coal sample.

Based on the analysis of the results obtained for the volatile matter content $V^{\text {daf }}$ and vitrinite reflectivity $R_{0}$, it was found that coal with a low degree of coalification is characterized by a high volatile matter content, and the higher the reflectivity, the lower the $V^{d a f}$. This relationship is not perfectly rectilinear, as $V^{\text {daf }}$ is also affected by the content of individual maceral groups, especially the ratio of vitrinite to inertinite [55].

\subsection{Sorption Analysis}

Sorption studies were conducted on coal samples, which are characterized by varying degrees of coalification and maceral composition. As a result, the kinetics of methane sorption for selected samples at a pressure of $0.1 \mathrm{MPa}$ were determined. For each of the determined sorption runs an attempt was made to fit the mathematical development of the unipore and bidisperse models. For both models, sorption runs were determined in the relationship $\frac{M_{t}}{M_{\infty}}(t)$, which were described based on Equations (3) and (11).

For both the unipore and bidisperse models, an unknown set of parameters $\frac{D_{e}}{R_{z}^{2}}$ and $\frac{D_{a}^{\prime}}{R_{a}^{2}}, \frac{D_{i}^{\prime}}{R_{i}^{2}}, \alpha, \frac{\beta}{\alpha}$, controlling the course of the sorption and diffusion processes, respectively, was sought. Parameters were identified by fitting model runs with data obtained from laboratory tests. Fitting the model runs with the experimental results was performed by minimizing the mean square error (MSE).

The results of fitting the unipore model to the experimental data are shown in Figure $4 \mathrm{a}-\mathrm{j}$, and for the bidisperse model in Figure $5 \mathrm{a}-\mathrm{j}$. Experimental data are indicated by red dots, which correspond to measurements made as shown in Section 3.3, while model runs are indicated by blue solid lines. The value of the mean squared error (MSE) enables the assessment of the validity of the chosen model. A value closer to 0 corresponds to a better fit in relation to the experimental data, which indicates the relevance of using the selected model. 


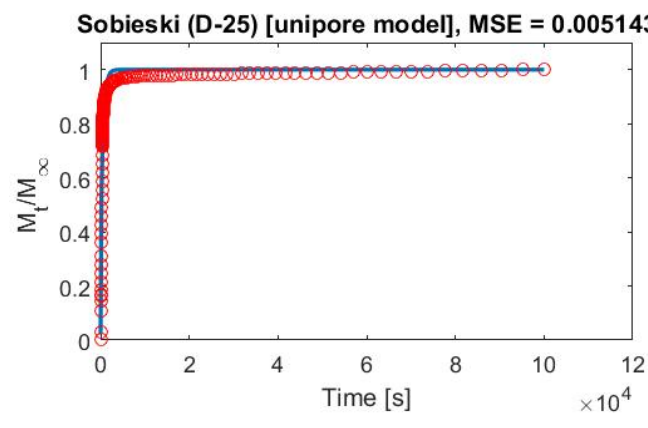

(a)

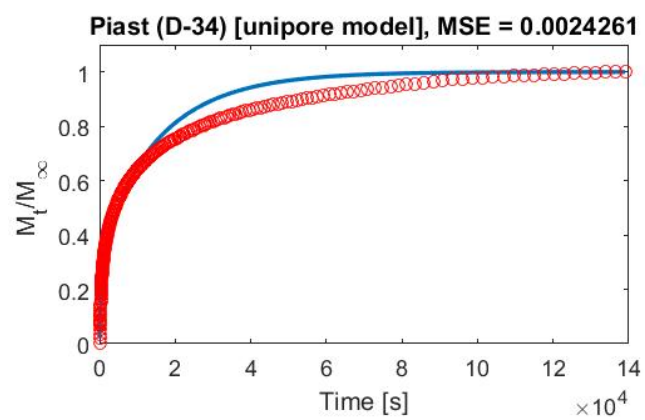

(c)

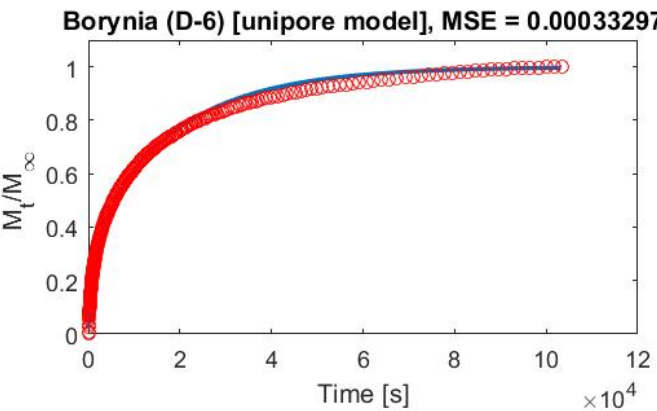

(e)

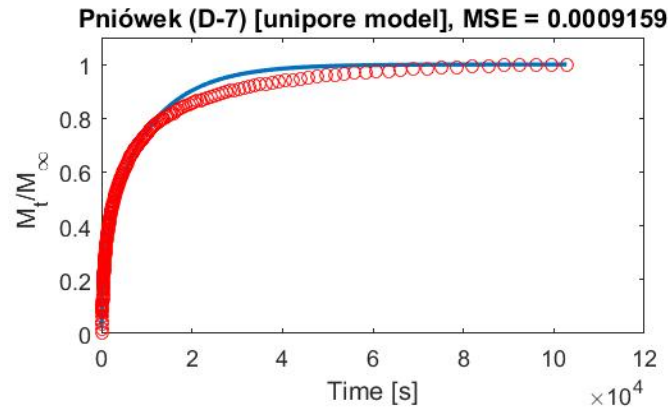

(g)

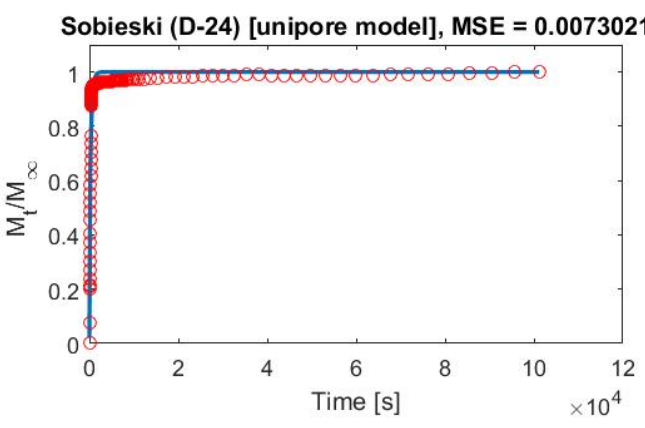

(b)

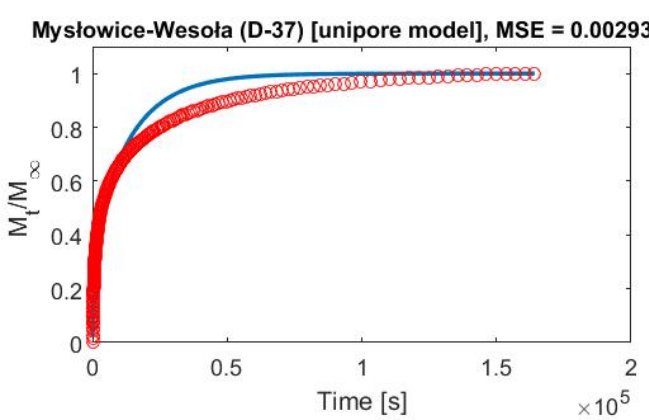

(d)

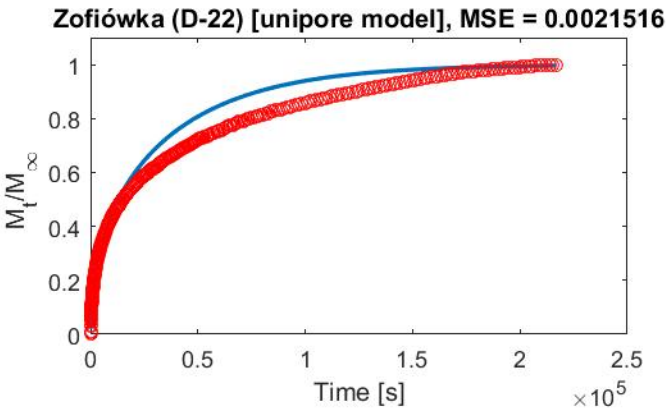

(f)

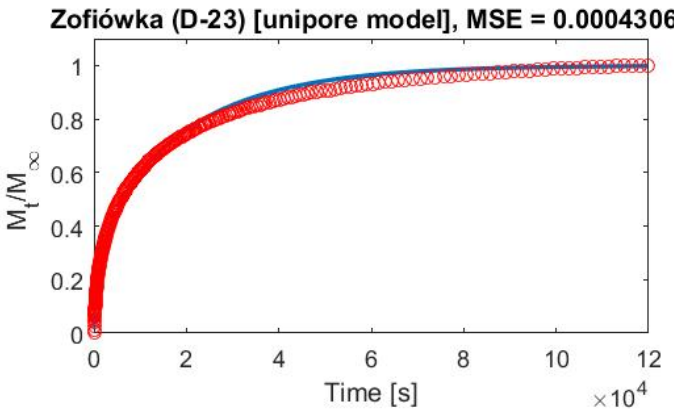

(h)

Figure 4. Cont. 


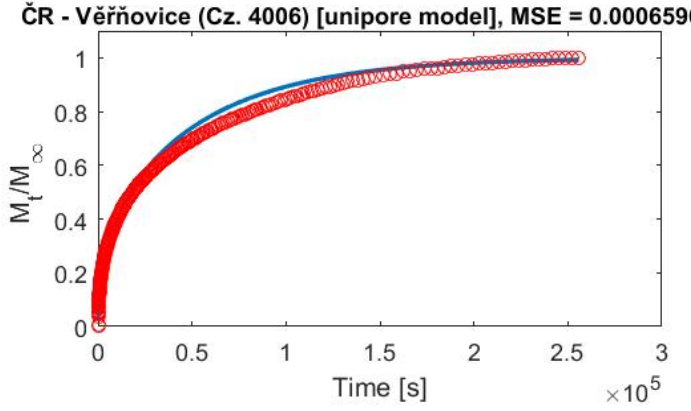

(i)

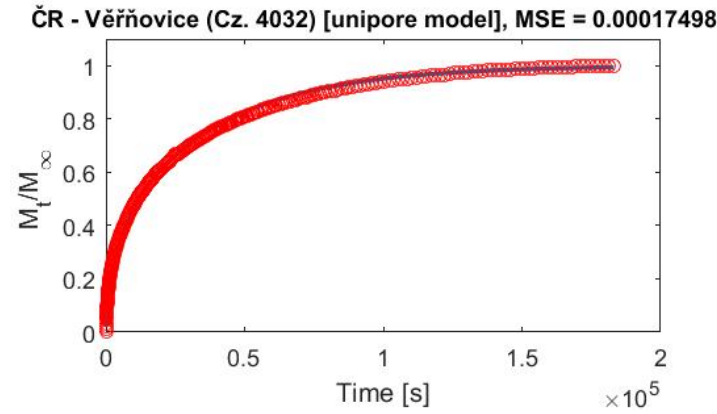

(j)

Figure 4. Fitting of the unipore model runs with experimental sorption data: (a) Sobieski (D-25); (b) Sobieski (D-24); (c) Piast (D-34); (d) Mysłowice-Wesoła (D-37); (e) Borynia (D-6); (f) Zofiówka (D-22); (g) Pniówek (D-7); (h) Zofiówka (D-23);

(i) ČR-Věřnovice (Cz. 4006); (j) ČR-Věřňovice (Cz. 4032).

Based on the analysis of the graphs (Figure $4 a-j$ ) and the results of the mean squared error (MSE) (Table 3), it was found that there is a relatively good fit of the model run for the unipore model with the experimental data for samples Cz. 4032, Cz. 4006, D-23, D-7 and D-6 for which the MSE values were $0.00018 ; 0.00066 ; 0.00043 ; 0.00092 ; 0.00033$, respectively. For the samples D-25, D-24, D-34, D-37 and D-22, the fit is not satisfactory and the MSE values were $0.005143 ; 0.00730 ; 0.00243 ; 0.00293 ; 0.00215$, respectively. Based on the above observations, it can be concluded that there is a relatively good fit for the unipore model for high rank coals and partially for medium rank coals. A dependence of the level of fit of the model run with the experimental data depending on the maceral composition was also observed. A satisfactory fit is found for coals with high vitrinite content, i.e., for samples Cz. 4032, Cz. 4006, D-23, D-7 and D-6. The exception was sample D-22 which, despite its high vitrinite content of $81.55 \%$, does not have a satisfactory fit. This may be due to the presence of cracks, which can be seen on the microscopic image (Figure 3f) and which disrupt the pore structure of this sample causing inhomogeneity.

Analysis of the dependence $\frac{D_{e}}{R_{2}^{2}}$ shows that for high rank coals its values are lower and range from $1.758 \times 10^{-6}$ to $2.559 \times 10^{-6}\left(\mathrm{~s}^{-1}\right)$. For medium rank coals these values increase and ranged from $2.344 \times 10^{-6}$ to $9.287 \times 10^{-6}\left(\mathrm{~s}^{-1}\right)$, while the highest values were recorded for low rank coals, from $5.990 \times 10^{-6}$ to $2.714 \times 10^{-4}\left(\mathrm{~s}^{-1}\right)$. Therefore, it can be concluded that the dependence $\frac{D_{e}}{R_{z}^{2}}$, which determines the rate of sorption processes in hard coal (its kinetics), depends on the degree of coalification and the maceral composition. The increase in the degree of coalification has the effect of reducing the $\frac{D_{e}}{R_{z}^{2}}$ dependence, which results in lower sorption kinetics of methane on hard coal. However, this is not a linear dependence, which is influenced by the varying maceral composition of the coals.

Based on the analysis of the literature, it can be stated that the petrography of coal has a significant influence on the course of sorption processes in its structure. The literature describes the dependence of the maceral composition and the degree of coalification on the course of diffusion and sorption processes [19,21,22,31,48,56-58]. The diffusivity of hard coal is related to both pore size distribution and porosity in terms of macroscopic equation. The organic matter has a strong methane-adsorption capacity. On the basis of research described in the literature $[59,60]$, it was found that the methane permeability for organic pores first decreases and then increases with the increase of pore size. 


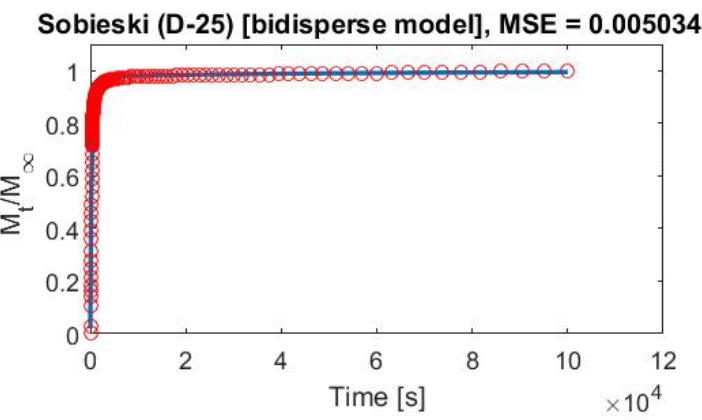

(a)

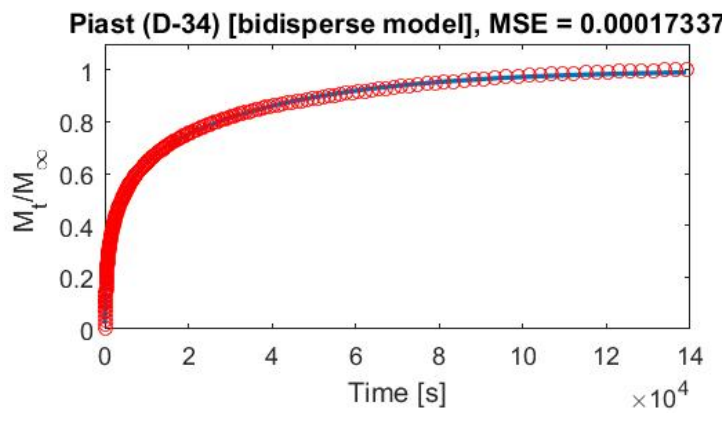

(c)

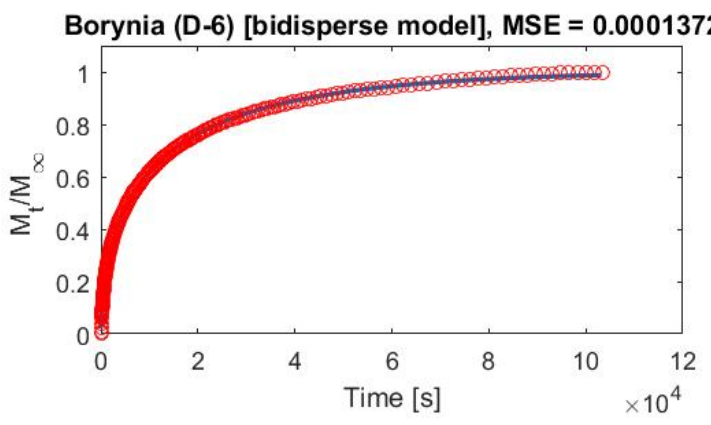

(e)

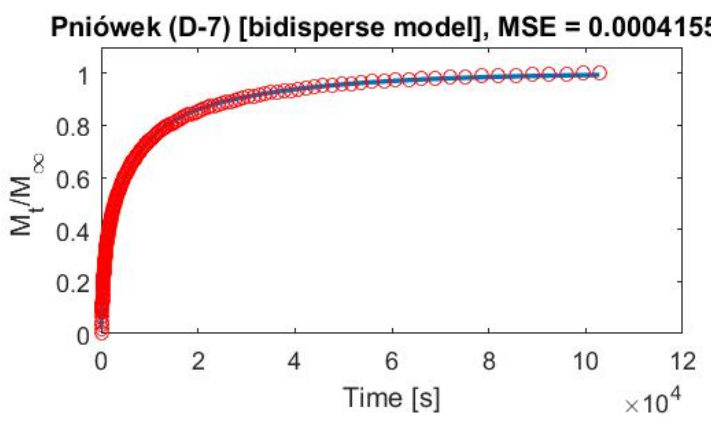

(g)

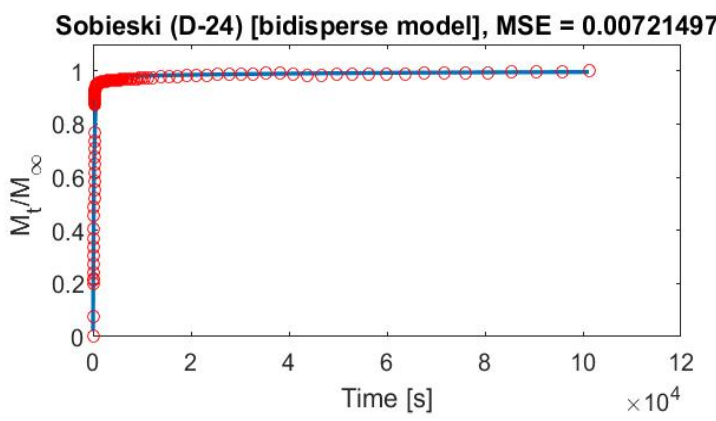

(b)

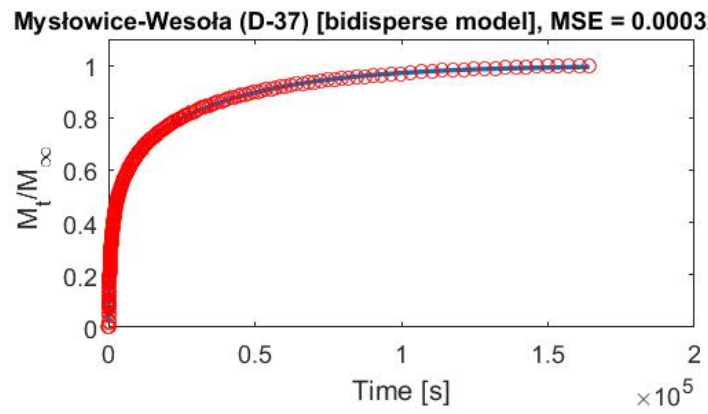

(d)

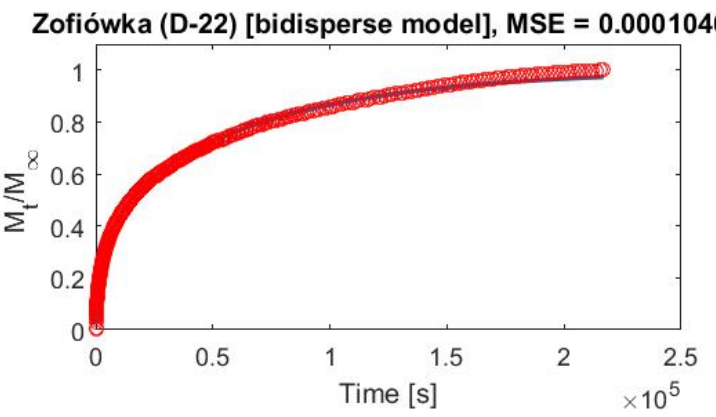

(f)

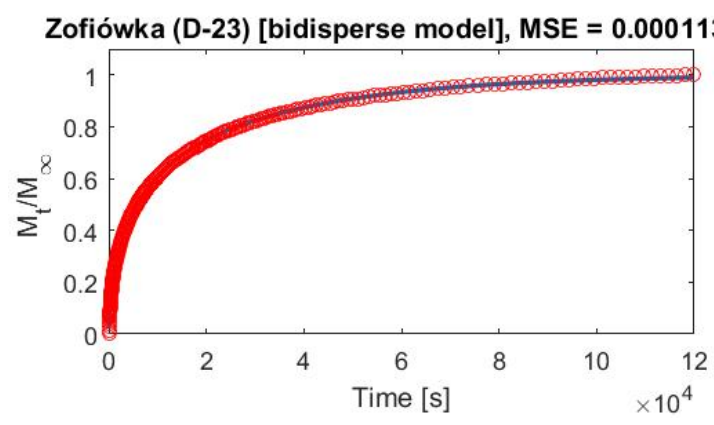

(h)

Figure 5. Cont. 


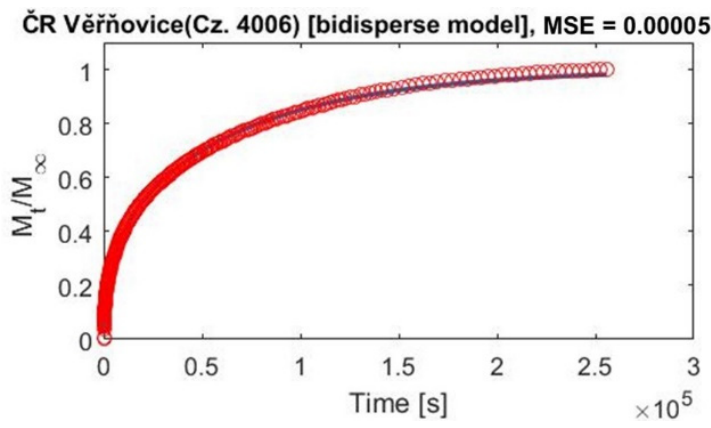

(i)

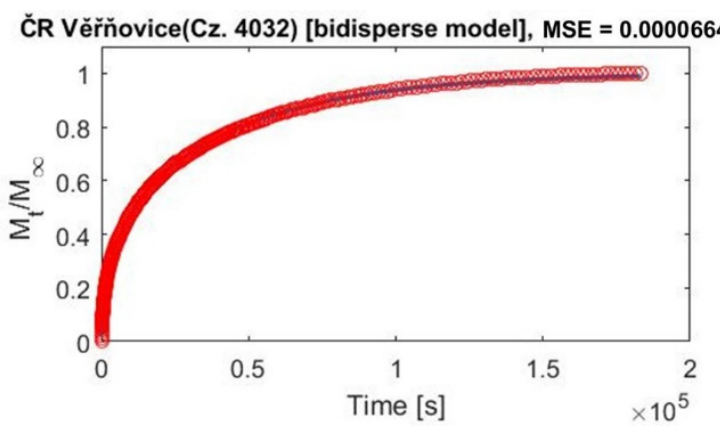

(j)

Figure 5. Fitting of the bidisperse model runs with experimental sorption data: (a) Sobieski (D-25); (b) Sobieski (D-24); (c) Piast (D-34); (d) Mysłowice-Wesoła (D-37); (e) Borynia (D-6); (f) Zofiówka (D-22); (g) Pniówek (D-7); (h) Zofiówka (D-23); (i) ČR-Věřňovice (Cz. 4006); (j) ČR-Věřňovice (Cz. 4032).

Table 3. The unipore diffusion model fitting parameters for the methane adsorption rate data at pressure $0.1 \mathrm{MPa}$.

\begin{tabular}{|c|c|c|c|c|c|}
\hline No. & Sample & $\frac{D_{e}}{R_{z}^{2}}\left[\mathbf{s}^{-1}\right]$ & $R_{z}(\mathrm{~cm})$ & $D_{e}\left(\mathrm{~cm}^{2} / \mathrm{s}\right)$ & MSE \\
\hline \multicolumn{6}{|c|}{ Low-rank coals } \\
\hline 1. & D-25 & $1.793 \times 10^{-4}$ & 0.011157 & $2.232 \times 10^{-8}$ & 0.00514 \\
\hline 2. & D-24 & $2.714 \times 10^{-4}$ & 0.011157 & $3.379 \times 10^{-8}$ & 0.00730 \\
\hline 3. & D-34 & $5.990 \times 10^{-6}$ & 0.011157 & $7.457 \times 10^{-10}$ & 0.00243 \\
\hline 4. & D-37 & $6.840 \times 10^{-6}$ & 0.011157 & $8.515 \times 10^{-10}$ & 0.00293 \\
\hline \multicolumn{6}{|c|}{ Medium-rank coals } \\
\hline 5. & D-6 & $5.087 \times 10^{-6}$ & 0.011157 & $6.333 \times 10^{-10}$ & 0.00033 \\
\hline 6. & D-22 & $2.344 \times 10^{-6}$ & 0.011157 & $2.918 \times 10^{-10}$ & 0.00215 \\
\hline 7. & $\mathrm{D}-7$ & $9.287 \times 10^{-6}$ & 0.011157 & $1.156 \times 10^{-9}$ & 0.00092 \\
\hline 8. & D-23 & $4.791 \times 10^{-6}$ & 0.011157 & $5.964 \times 10^{-10}$ & 0.00043 \\
\hline \multicolumn{6}{|c|}{ High-rank coals } \\
\hline 9. & Cz. 4006 & $1.758 \times 10^{-6}$ & 0.011157 & $2.188 \times 10^{-10}$ & 0.00066 \\
\hline 10. & Cz. 4032 & $2.559 \times 10^{-6}$ & 0.011157 & $3.185 \times 10^{-10}$ & 0.00018 \\
\hline
\end{tabular}

Previous studies have shown that pore size distribution may have a significant impact on the gas sorption rate for coal samples. A sample that is homogeneous in terms of pore size distribution can be well fitted by simple diffusion models based on the unipore structure $[30,61]$. This was confirmed in the research presented in this paper, which was proved by the indication of a good fit of the unipore model to the experimental data for highly coalified samples Cz. 4006 and Cz. 4032. They were characterized by a maceral composition with a visible predominance of vitrinite, which is characterized by a micropore structure. A thesis describing the influence of coal petrography on sorption properties was also presented by Ceglarska-Stefańska [48], describing the effect of pore size distribution dependence in individual macerals. Furthermore, this thesis showed that vitrinite is a microporous material, while inertinite contains a significant proportion of meso- and macropores. Studies on the effect of maceral composition on sorption processes were also conducted by Crosdale [21], who found that inertinite-rich coals, especially fusinite and semifusinite, exhibit high gas emission rates, while vitrinite-rich coals exhibit slower emission rates. The studies described in this paper confirm the above thesis. The analysed coal samples for which high values of vitrinite content were obtained required more time to reach the sorption equilibrium state. For samples Cz. 4006 and Cz. 4032 with vitrinite contents of $91.29 \%$ and $88.18 \%$, the values of effective diffusion coefficient $D_{e}$ $2.188 \times 10^{-10}$ and $3.185 \times 10^{-10} \mathrm{~cm}^{2} / \mathrm{s}$ were obtained, which were determined based on 
the unipore model. Low values of the effective diffusion coefficient result from slower sorption processes occurring in these samples. The above observations also confirm the thesis concerning the predominance of the processes occurring in the micropores in the structures having a predominance of macerals from the vitrinite group. Modelling by Crosdale [21] indicates that bright and dull coals behave differently during gas desorption. The applicability of the unipore model to the desorption of bright coals suggests that the micropore system plays a dominant role here. The desorption described by the bidisperse model is suitable for dull coals rich in inertinite, especially semifusinite.

The low level of fit of the mathematical development of the unipore model with the experimental data for coals with a low degree of coalification is indicative of their extensive pore structure (Table 3). This is evident in the analysis of the maceral composition of these samples. For the low rank coals, the vitrinite content ranged from $47.56 \%$ to $64.99 \%$ and inertinite content ranged from $24.27 \%$ to $39.68 \%$ (Table 2). As stated in this paper and the literature presented above, an important parameter that differentiates coal in terms of its sorption properties is the content of each maceral group. Vitrinite is a microporous maceral with high sorption capacity, and sorption processes occur quite slowly in it. Inertinite, especially one with large and hollow cells, has high macroporosity and negligible microporosity. Therefore, for coals with different maceral composition and a low degree of coalification, it is necessary to treat their structure as bidisperse, for which sorption and diffusion processes occur simultaneously in micro- and macropores.

The fit of the bidisperse model runs to the experimental data for each of the analysed samples gave good results, as shown in the graphs (Figure $5 a-j$ ). This is further confirmed by the low values of the mean squared error MSE obtained, which ranged from $5.152 \times 10^{-5}$ to 0.00721 (Table 4 ).

Table 4. The bidisperse diffusion model fitting parameters for the methane adsorption rate data at pressure $0.1 \mathrm{MPa}$.

\begin{tabular}{|c|c|c|c|c|c|c|}
\hline No. & Sample & $\frac{D_{a}^{\prime}}{R_{a}^{2}}\left[\mathbf{s}^{-1}\right]$ & $\frac{D_{i}^{\prime}}{R_{i}^{2}}\left[\mathbf{s}^{-1}\right]$ & $\alpha$ & $\frac{\beta}{\alpha}$ & MSE \\
\hline \multicolumn{7}{|c|}{ Low-rank coals } \\
\hline 1. & D-25 & $1.923 \times 10^{-4}$ & $7.192 \times 10^{-7}$ & 0.788472 & 0.0682 & 0.00503 \\
\hline 2. & D-24 & $2.836 \times 10^{-4}$ & $2.244 \times 10^{-7}$ & 0.014057 & 0.0392 & 0.00721 \\
\hline 3. & D-34 & $3.725 \times 10^{-5}$ & $7.137 \times 10^{-6}$ & 0.386631 & 6.1462 & 0.00017 \\
\hline 4. & D-37 & $3.471 \times 10^{-5}$ & $5.273 \times 10^{-6}$ & 0.492207 & 4.6148 & 0.00033 \\
\hline \multicolumn{7}{|c|}{ Medium-rank coals } \\
\hline 5. & D-6 & $1.330 \times 10^{-5}$ & $3.289 \times 10^{-3}$ & 0.001063 & 7.2988 & 0.00014 \\
\hline 6. & $\mathrm{D}-22$ & $2.115 \times 10^{-5}$ & $2.197 \times 10^{-3}$ & 0.006380 & 20.3650 & 0.00010 \\
\hline 7. & $\mathrm{D}-7$ & $1.841 \times 10^{-5}$ & $8.396 \times 10^{-4}$ & 0.004401 & 2.2815 & 0.00042 \\
\hline 8. & D-23 & $1.486 \times 10^{-5}$ & $8.205 \times 10^{-4}$ & 0.003880 & 7.7398 & 0.00011 \\
\hline \multicolumn{7}{|c|}{ High-rank coals } \\
\hline 9. & Cz. 4006 & $3.295 \times 10^{-5}$ & $1.237 \times 10^{-3}$ & 0.001090 & 38.9386 & $5.152 \times 10^{-6}$ \\
\hline 10. & Cz. 4032 & $1.695 \times 10^{-5}$ & $1.970 \times 10^{-3}$ & 0.001132 & 33.0460 & $6.649 \times 10^{-6}$ \\
\hline
\end{tabular}

Table 4 summarizes the fitting parameters of the bidisperse model along with the value of the mean squared error MSE. The values of effective diffusivity of macropores $\frac{D_{a}^{\prime}}{R_{a}^{2}}$, effective diffusivity of micropores $\frac{D_{i}^{\prime}}{R_{i}^{2}}$, and dimensionless parameters are presented: $\alpha$ represents the ratio of the time scales of the processes taking place in the micro- and macropores, and $\frac{\beta}{\alpha}$ specifying the information concerning the ratio of the micro- and macropores uptakes at equilibrium [43].

The hypothesis, presented above in connection with the unipore model, that the rate of methane sorption on hard coal decreases with an increase in the degree of coalification appears to be correct. It was confirmed by the obtained values of $\frac{D_{a}^{\prime}}{R_{a}^{2}}$ and $\frac{D_{i}^{\prime}}{R_{i}^{2}}$ for the samples with a high degree of coalification, where the dominance of effective micropore diffusivity 
$\frac{D_{i}^{\prime}}{R_{i}^{2}}$ responsible for the sorption processes occurring in the micropores, where the process is slower, is visible. One example is the sample Cz. 4032 for which the effective diffusivity of micropores $\frac{D_{i}^{\prime}}{R_{i}^{2}}$ was $1.970 \times 10^{-3}\left(\mathrm{~s}^{-1}\right)$, while the effective diffusivity of macropores $\frac{D_{a}^{\prime}}{R_{a}^{2}}$ was $1.695 \times 10^{-5}\left(\mathrm{~s}^{-1}\right)$, which confirms the advantage of micropores in its structure. This is also confirmed by the maceral composition results obtained (Table 2). For the analysed high rank coals, there is a predominance of vitrinite (88.18-91.29\%) over other macerals.

In the case of medium rank coals, for which vitrinite content ranged from 73.82 to $87.65 \%$ and inertinite content from 9.53 to $24.09 \%$, the advantage of sorption processes occurring in micropores over macropores was also observed. For these samples, the effective micropore diffusivity $\frac{D_{i}^{\prime}}{R_{i}^{2}}$ ranged from $3.289 \times 10^{-3}$ to $2.197 \times 10^{-4}\left(\mathrm{~s}^{-1}\right)$, while the effective macropore diffusivity $\frac{D_{a}^{\prime}}{R_{a}^{2}}$ ranged from $1.330 \times 10^{-5}$ to $2.115 \times 10^{-5}\left(\mathrm{~s}^{-1}\right)$. The highest value of effective macroporous diffusivity of $2.115 \times 10^{-5}\left(\mathrm{~s}^{-1}\right)$ was observed for sample D-22. As mentioned before, its structure shows areas of cracks (Figure 3f), which may explain the increased value of this parameter.

For the analysed coals with a low degree of coalification, the maceral composition was different compared to the previously discussed samples, where a higher content of inertinite was observed. Vitrinite content ranged from $47.56 \%$ to $64.99 \%$ and inertinite content ranged from $24.27 \%$ to $39.68 \%$. The predominance of sorption contribution in macropores over micropores is evident for these samples. The values of effective micropore diffusivity $\frac{D_{i}^{\prime}}{R_{i}^{2}}$ ranged from $2.244 \times 10^{-7}$ to $7.137 \times 10^{-6}\left(\mathrm{~s}^{-1}\right)$, while the effective macropore diffusivity $\frac{D_{a}^{\prime}}{R_{a}^{2}}$ ranged from $3.471 \times 10^{-5}$ to $2.836 \times 10^{-4}\left(\mathrm{~s}^{-1}\right)$. Attention should be paid to sorption runs for samples D-24 and D-25 (Figure 5a,b). They show higher dynamics than the others, which are connected with a larger share of sorption in macropores for which the values of effective macropore diffusivity were $2.836 \times 10^{-4}$ and $1.923 \times 10^{-4}\left(\mathrm{~s}^{-1}\right)$, respectively.

Ruckenstein and Dang [32,43] stated that the parameter $\alpha$ (Table 4) represents the ratio of the time scales of the processes taking place in the micro- and macropores. For $\alpha$ values falling within the range of 0.001 to 100, it is apparent that the simultaneous diffusion of micro- and macropores controls the adsorption process. Studies by Roberts and York [62] have shown that sorption and diffusion processes occur in both micro- and macropores when the value of $\alpha$ occurs between 0.1 and 1.0. The results of the $\alpha$ coefficient presented in the article show that the diffusion processes for the analysed coal samples should be considered in terms of the bidisperse structure. Its values ranged from 0.001090 to 0.788472 . Lower values for $\alpha$ occurring at the limit of 0.001 occurred for coals with a high degree of coalification and a certain predominance of sorption processes in micropores. Conversely, higher values of $0.5-0.8$ were observed for low rank coals, in which the predominance of sorption processes in macropores was determined. Therefore, it can be stated that lower values of $\alpha$ coefficient were found for coal samples in which sorption processes took place predominantly in micropores, whereas higher values, closer to 1 , were found for coals in which macropores were dominant in sorption processes.

Ruckenstein and Dang [32,43] defined the $\frac{\beta}{3 \alpha}$ dependence shown in Equation (11), specifying the information concerning the ratio of the micro- and macropores $\left(M_{i} / M_{a}\right)$ uptakes at equilibrium $\frac{M_{t}}{M_{\infty}}=1$. They also defined that for low values of $\frac{\beta}{3 \alpha}$ there is negligible adsorption of micropores, while for high values there is neglible adsorption of macropores. Thus, the adsorption ratio of micropores and macropores $\left(M_{\mathrm{i}} / M_{a}\right)$ at sorption equilibrium can be described by the equation [32]:

$$
\frac{M_{i}}{M_{a}}=\frac{\beta}{3 \alpha}
$$


where $M_{i}$-the adsorption rate of methane in micropores at equilibrium, $M_{a}$-the adsorption rate of methane in macropores at equilibrium.

The determined value of $\frac{\beta}{\alpha}$ (Table 4 ) is obtained by fitting the bidisperse model to the experimental data obtained as a result of the research. The analysis of the research results presented in the article (Table 4), to some extent confirms the above thesis. For coals in which sorption processes were found to be dominant in macropores, the $\frac{\beta}{\alpha}$ results ranged from 0.0682 to 6.1462 , which may indicate a lower proportion of micropores in their structure. On the contrary, for coals with predominance of sorption processes in the micropores, the values of the $\frac{\beta}{\alpha}$ coefficient ranged between 33.0460 and 38.9386, which may confirm a smaller share of macropores in their structure.

\section{Conclusions}

On the basis of the studies carried out, it has been stated that the mechanism of the occurrence of processes of sorption and diffusion of methane on hard coal is related to the petrography of coal, in particular to the maceral composition and the degree of coalification. The applicability of one of the models (unipore or bidisperse) describing the phenomenon of gas sorption and diffusion in a carbon structure is related to its structure and the relationship between micro- and macropores. The above fact supports the need for research on the applicability of the compared models. Based on the research conducted, the following conclusions were formed:

1. The pore size distribution has a significant impact on the rate of gas sorption processes in the coal structure. Coals homogeneous in terms of pore size distribution can be well fitted with simple diffusion models based on the unipore pore structure. Such coals are characterized by a high degree of coalification and a homogeneous maceral composition with a visible predominance of one of the maceral groups. The possibility of using the unipore model to describe the sorption of bright coals suggests that the micropore system plays a dominant role in their structure.

2. Bidisperse sorption is indicated for dull coals rich in inertinite, especially semifusinite. Coals with a complex structure, in which sorption and diffusion occur simultaneously in micro- and macropores, must be described by a bidisperse model, which has a better fit to the real course of sorption kinetics.

3. The application of the unipore model is possible for high rank coals, characterized by structures with vitrinite predominating. Conditionally, it can be applied to medium rank coals on the condition of high vitrinite content, indicating the predominance of micropores in the structure.

4. For low rank coals, it is necessary to use a bidisperse model to properly describe the course of sorption processes. The bidisperse model provides a good fit for all analysed coal types, regardless of the ratio of individual maceral groups.

5. Hard coal with a low degree of coalification is characterized by a high volatile matter content $V^{\text {daf }}$, and as the vitrinite reflectivity $R_{0}$ increases, $V^{\text {daf }}$ decreases. This correlation is not perfectly rectilinear, as $V^{\text {daf }}$ is also affected by the content of individual maceral groups, especially the ratio of vitrinite to inertinite.

Author Contributions: Conceptualization, M.K., J.K. and K.G.; methodology, M.K. and K.G.; validation, M.K. and T.S.; formal analysis, M.K.; investigation, M.K., K.G., T.S. and J.Š.; resources, M.K. and K.G.; data curation, M.K. and K.G.; writing—original draft preparation, M.K.; writing—review and editing, M.K., J.K. and K.G.; supervision, J.K. All authors have read and agreed to the published version of the manuscript.

Funding: This research was funded by the Ministry of Science and Higher Education, Poland Research Project (11333020).

Institutional Review Board Statement: Not applicable.

Informed Consent Statement: Not applicable. 
Data Availability Statement: The data presented in this study are available on request from the corresponding author.

Acknowledgments: We would like to thank the Institute of Geonics in Ostrava for their help in reflectance analyses.

Conflicts of Interest: The authors declare no conflict of interest. The funders had no role in the design of the study; in the collection, analyses, or interpretation of data; in the writing of the manuscript; or in the decision to publish the results.

\section{References}

1. U.S. Energy Information Administration, International Energy Statistics. Available online: https://www.eia.gov/international/ data/world/electricity / electricity-consumption (accessed on 6 December 2021).

2. Norby, R.J.; Luo, Y. Evaluating ecosystem responses to rising atmospheric $\mathrm{CO}_{2}$ and global warming in a multi-factor world. New Phytol. 2004, 162, 281-293. [CrossRef]

3. Perera, F. Pollution from Fossil-Fuel Combustion is the Leading Environmental Threat to Global Pediatric Health and Equity: Solutions Exist. Int. J. Environ. Res. Public Health 2018, 15, 16. [CrossRef] [PubMed]

4. Paraschiv, S.; Paraschiv, L.S. Trends of carbon dioxide $\left(\mathrm{CO}_{2}\right)$ emissions from fossil fuels combustions (coal, gas and oil) in the EU member states from 1960 to 2018. Energy Rep. 2020, 6, 237-242. [CrossRef]

5. Borowski, M.; Życzkowski, P.; Cheng, J.; Łuczak, R.; Zwolińska, K. The combustion of Methane from Hard Coal Seams in Gas Engines as a Technology Leading to Reducing Greenhouse Gas Emissions-Electricity Prediction Using ANN. Energies 2020, 13, 4429. [CrossRef]

6. Tutak, M.; Brodny, J. Forecasting Methane Emissions from Hard Coal Mines Including the Methane Drainage Process. Energies 2019, 12, 3840. [CrossRef]

7. Gonet, A.; Nagy, S.; Rybicki, C.; Siemek, J.; Stryczek, S.; Wiśniowski, R. Coal bed methane extraction technology (CBM). Górnictwo $i$ Geol. 2010, 5, 5-25.

8. Ahmed, A.; Johnston, J.S.; Boyer, C.; Lambert, S.W.; Bustos, O.A.; Pashin, J.C.; Wray, A. Coalbed methane: Clean energy for the world. Oilfield Rev. 2009, 21, 4-13.

9. Busch, A.; Gensterblum, Y. CBM and CO2-ECBM related sorption processes in coal: A review. Int. J. Coal Geol. 2011, 87, 48-71. [CrossRef]

10. Zou, C. Chapter 2-Meaning of Unconventional Petroleum Geology. Unconventional Petroleum Geology, 2nd ed.; Petroleum Industry Press: Beijing, China, 2017; pp. 49-95.

11. Hadro, J.; Wójcik, I. Coalbed methane: Resources and exploitation. Przegląd Geol. 2013, 61, 404-410.

12. Słoczyński, T.; Drozd, A. Coalbed methane (CBM)—World experience and development prospects in Poland. Naft. $i$ Gaz 2017, 11, 851-856. [CrossRef]

13. Karbownik, M.; Krause, E. Tests of methane desorption and emission from samples of hard coal in the context of mine closures through flooding. J. Sustain. Min. 2019, 18, 127-133. [CrossRef]

14. Harpalani, S.; Chen, G. Influence of gas production induced volumetric strain on permeability of coal. Geotech. Geol. Eng. 1997, 15, 303-325. [CrossRef]

15. Robertson, E.P. Measurement and Modeling of Sorption-Induced Strain and Permeability Changes in Coal; Idaho National Laboratory: Idaho Falls, ID, USA, 2005.

16. Zhou, F.B.; Xia, T.Q.; Wang, X.; Zhang, Y.; Sun, Y.; Liu, J. Recent developments of coal mine methane extraction and utilization in China: A review. J. Nat. Gas Sci. Eng. 2016, 31, 437-458. [CrossRef]

17. Wierzbicki, M.; Skoczylas, N. Selected methods of determining the effective diffusion coefficient on the basis of the kinetics of saturation/gas release from a coal sample. Pract. Inst. Mech. Górotworu PAN 2010, 12, 43-50.

18. Hobler, T. Diffusive Mass Movement and Absorbers; Wydawnictwo Naukowo-Techniczne: Warszawa, Poland, 1976.

19. Keshavarz, A.; Sakurovs, R.; Grigore, M.; Sayyafzadeh, M. Effect of maceral composition and coal rank on gas diffusion in Australian coals. Int. J. Coal Geol. 2017, 173, 65-75. [CrossRef]

20. Crank, J. The Mathematics of Diffusion, 2nd ed.; Oxford University Press: London, UK, 1975; p. 414.

21. Crosdale, P.J.; Beamish, B.B.; Valix, M. Coalbed methane sorption related to coal composition. Int. J. Coal Geol. 1998, 35, 147-158. [CrossRef]

22. Laxminarayana, C.; Crosdale, P.J. Role of coal type and rank on methane sorption characteristics of Bowen Basin, Australia coals. Int. J. Coal Geol. 1999, 40, 309-325. [CrossRef]

23. Godyń, K.; Dutka, B. The impact of the degree of coalification on the sorption capacity of coals from the Zofiówka Monocline. Arch. Min. Sci. 2018, 63, 727-746. [CrossRef]

24. Godyń, K.; Dutka, B.; Chuchro, M.; Młynarczuk, M. Synergy of Parameters Determining the Optimal Properties of Coal as a Natural Sorbent. Energies 2020, 13, 1967. [CrossRef]

25. Karbownik, M.; Krawczyk, J.; Schlieter, T. The Unipore and Bidisperse Diffusion Models for Methane in Hard Coal Solid Structures Related to the Conditions in the Upper Silesian Coal Basin. Arch. Min. Sci. 2020, 65, 591-603. [CrossRef] 
26. Dutka, B.; Godyń, K. Coalification as a Process Determining the Methane Adsorption Ability of Coal Seams. Arch. Min. Sci. 2021, 66, 181-195. [CrossRef]

27. Bukowska, M.; Senetra, U.; Wadas, M. Chronostratigraphic and Depth Variability of Porosity and Strength of Hard Coals in the Upper Silesian Basin. Gospod. Surowcami Miner. 2012, 28, 151-166. [CrossRef]

28. Busch, A.; Gensterblum, Y.; Krooss, B.M.; Littke, R. Methane and carbon dioxide adsorption-diffusion experiments on coal: Upscaling and modeling. Int. J. Coal Geol. 2004, 60, 151-168. [CrossRef]

29. Li, D.; Liu, Q.; Weniger, P.; Gensterblum, Y.; Busch, A.; Krooss, B.M. High-pressure sorption isotherms and sorption kinetics of $\mathrm{CH} 4$ and $\mathrm{CO} 2$ on coals. Fuel 2010, 89, 569-580. [CrossRef]

30. Clarkson, C.R.; Bustin, R.M. The effect of pore structure and gas pressure upon the transport properties of coal: A laboratory and modeling study. 2. Adsorption rate modeling. Fuel 1999, 78, 1345-1362. [CrossRef]

31. Pan, Z.; Connell, L.D.; Camilleri, M.; Connelly, L. Efects of matrix moisture on gas diffusion and flow in coal. Fuel 2010, 89, 3207-3217. [CrossRef]

32. Dang, W.; Zhang, J.; Wei, X.; Tang, X.; Wang, C.; Chen, Q.; Lei, Y. Methane Adsorption Rate and Diffusion Characteristics in Marine Shale Samples from Yangtze Platform, South China. Energies 2017, 10, 626. [CrossRef]

33. Li, C.; Nie, Y.; Tian, J.; Zhao, Y.; Zhang, X. The Impact of Equilibrium Gas Pressure and Coal Particle Size on Gas Dynamic Diffusion in Coal. Processes 2019, 7, 571. [CrossRef]

34. Cui, X.; Bustin, R.M.; Dipple, G. Selective transport of $\mathrm{CO}_{2}, \mathrm{CH}_{4}$, and $\mathrm{N}_{2}$ in coals: Insights from modeling of experimental gas adsorption data. Fuel 2004, 83, 293-303. [CrossRef]

35. Krause, E.; Wierzbiński, K. Studies on sorption kinetics of coals from seams threatened by methane and rock outbursts. In Proceedings of the XIII International Scientific and Technical Conference GZN, Ustron, Poland, 7-8 November 2006.

36. Wierzbicki, M.; Skoczylas, N.; Kudasik, M. The Use of a Unipore Diffusion Model to Describe the Kinetics of Methane Release from Coal Spoil in the Longwall Environment. Studia Geotech. Et Mech. 2017, 39, 81-89. [CrossRef]

37. Pillalamarry, M.; Harpalani, S.; Liu, S. Gas diffusion behavior of coal and its impact on production from coalbed methane reservoirs. Int. J. Coal Geol. 2011, 86, 342-348. [CrossRef]

38. Jian, X.; Guan, P.; Zhang, W. Carbon dioxide sorption and diffusion in coals: Experimental investigation and modeling. Sci. China Earth Sci. 2012, 55, 633-643. [CrossRef]

39. Švábová, M.; Weishauptová, Z.; Přibyl, O. The effect of moisture on the sorption process of $\mathrm{CO}_{2}$ on coal. Fuel 2012, 92, 187-196. [CrossRef]

40. Pone, J.D.N.; Halleck, P.M.; Mathews, J.P. Sorption capacity and sorption kinetic measurements of $\mathrm{CO}_{2}$ and $\mathrm{CH}_{4}$ in confined and unconfined bituminous coal. Energy Fuels 2009, 23, 4688-4695. [CrossRef]

41. Yang, X.; Wang, G.; Zhang, J.; Ren, T. The Influence of Sorption Pressure on Gas Diffusion in Coal Particles: An Experimental Study. Processes 2019, 7, 219. [CrossRef]

42. Timofiejew, D.P. Adsprptionskinetik; VEB: Leipzig, Germany, 1967.

43. Ruckenstein, E.; Vaidyanathan, A.S.; Youngquist, G.R. Sorption by solids with bidisperse pore structure. Chem. Eng. Sci. 1971, 26, 1305-1318. [CrossRef]

44. Shi, J.Q.; Durucan, S. A bidisperse pore diffusion model for methane displacement desorption in coal by $\mathrm{CO}_{2}$ injection. Fuel 2003, 82, 1219-1229. [CrossRef]

45. Siemons, N.; Wolf, K.H.A.A.; Bruining, J. Interpretation of carbon dioxide diffusion behavior in coals. Int. J. Coal Geol. 2007, 72, 315-324. [CrossRef]

46. Wang, G.D.; Ren, T.; Qi, Q.X.; Zhang, L.; Liu, Q.Q. Prediction of Coalbed Methane (CBM) Production Considering Bidisperse Diffusion: Model Development, Experimental Test, and Numerical Simulation. Energy Fuels 2017, 31, 5785-5797. [CrossRef]

47. Czerw, K.; Ćwik, A.; Baran, P.; Zaręsska, K. Kinetics of methane and carbon dioxide sorption and sorption-induced expansion of coal-kinetic equations assessment. E3S Web Conf. 2016, 10, 1-7. [CrossRef]

48. Ceglarska-Stefańska, G.; Nodzeński, A.; Hołda, S. Studies on coal-gas system in the aspect of methane extraction and $\mathrm{CO}_{2}$ sequestration. Gospod. Surowcami Miner. 2007, 23, 51-59.

49. ISO 7404-2:2009; Methods for the Petrographic Analysis of Coals-Part 2: Methods of preparing Coal Samples; ISO: Geneva, Switzerland, 2009.

50. ISO 7404-3:2009; Methods for the Petrographic Analysis of Coals_Part 3: Method of Determining Maceral Group Composition; ISO: Geneva, Switzerland, 2009.

51. SO 7404-5:2009; Methods for the Petrographic Analysis of Coals-Part 5: Method of Determining Microscopically the Reflectance of Vitrinite; ISO: Geneva, Switzerland, 2009.

52. PL-PKN. PN-G-04516:1998 Solid Fuels—Determination of Volatile Matter Content by Balance Method; PL-PKN: Warszawa, Poland, 1998.

53. Mianowski, A.; Marecka, A. The isokinetic effect as related to the activation energy for the gases diffusion in coal at ambient temperatures. J. Therm. Anal. Calorim. 2009, 96, 285-292. [CrossRef]

54. Stach, E.; Mackowsky, M.T.; Teichmuller, M.; Taylor, G.H.; Chandra, D.; Teichmuller, R. Stach's Textbook of Coal Petrology; Gebruder Borntraeger: Berlin, Germany, 1982.

55. Probierz, K.; Marcisz, M.; Sobolewski, A. From Peat to Coking Coals in the Zofiówka Monocline in the Jastrzębie Area (South-Western Part of the Upper Silesian Coal Basin); Publishing House of the Institute for Chemical Processing of Coal: Zabrze, Poland, 2012. 
56. Crosdale, P.J.; Beamish, B.B. Methane diffusivity at South Bulli (NSW) and Central (Qld) collieries in relation to coal maceral composition. In Proceedings of the International Symposium-Cum-Workshop On Management and Control of High Gas Emissions and Outbursts in Underground Coal Mines, Wollongong, Australia, 20-24 March 1995; pp. 363-367.

57. Olajossy, A. On the effects of maceral content on methane sorption capacity in coals. Arch. Min. Sci. 2013, 58, 1221-1228. [CrossRef]

58. Godyń, K.; Dutka, B. Sorption and Micro-Scale Strength Properties of Coals usceptible to Outburst Caused by Changes in Degree of Coalification. Materials 2021, 14, 5807. [CrossRef]

59. Song, W.; Yao, B.; Yao, J.; Li, Y.; Sun, H.; Yang, Y.; Zhang, L. Methane surface diffusion capacity in carbon-based capillary with application to organic-rich shale gas reservoir. Chem. Eng. J. 2018, 352, 644-654. [CrossRef]

60. Zhu, Q.; Song, W.; Yang, Y.; Lu, X.; Liu, L.; Zhang, Y.; Sun, H.; Yao, J. An Advection-diffusion-mechanical deformation integral model to predict coal matrix methane permeability combining digital rock physics with laboratory measurements. Appl. Geochem. 2021, 126, 104861. [CrossRef]

61. Yuan, W.; Pan, Z.; Xiao, L.; Yang, Y.; Zhao, C.; Connell, L.D.; Li, S.; He, J. Experimental study and modelling of methane adsorption and diffusion in shale. Fuel 2014, 117, 509-519. [CrossRef]

62. Roberts, P.V.; York, R. Adsorption of Normal Paraffins from Binary Liquid Solutions by 5A Molecular Sieve. Ind. Eng. Chem. Process Des. Dev. 1967, 6, 516-525. [CrossRef] 